\title{
Comparison of Experimental and Literature models for the Heat Gain through the Walls in terms of the Effect of Thermophysical Properties
}

\author{
Hasan Oktay ${ }^{1}$, Hakan Tutumlu ${ }^{2}$, and Recep Yumrutaş ${ }^{3}$
}

\begin{abstract}
In literature, many investigations are presented arguing to find the influence of each thermophysical property of building components on the dynamic thermal characteristics, while the properties have been assumed as independent of each other. In this study, the effect of each property on heat gain value utilising relationships between the measurement values of thermophysical properties of building materials. In the previous study, 102 new concrete wall samples were produced and their thermophysical properties were tested in accordance with ASTM and EN standards. In this study, the heat gain values through the structures are computed from the solution of the problem by Complex Finite Fourier Transform (CFFT) technique by using both the obtained those expressions and assumptions proposed from the literature and comparisons have been made. The results show that the assumptions are not realistic in a significant number of cases.
\end{abstract}

Keywords - Building structure, concrete, heat gain, CFFT, thermophysical properties.

\section{INTRODUCTION}

A a great amount of total energy consumption in the world

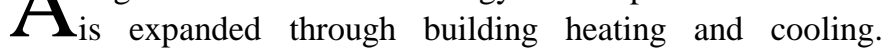
Building energy requirements for the winter and summer seasons constitutes a loss or gain through windows, walls, roofs, infiltration and equipment used. In many buildings, walls and roofs are responsible for a major fraction of heat loss or gains for the heating or cooling loads due to their large surface area [1]. Therefore, it is critical both to improve the thermal performance of these structures and to improve thermal comfort of the occupants in terms of reducing the energy use.

In order to describe the thermal performance of the opaque envelope components, studies have been conducted to identify the dynamic thermal characteristics of the components as time

Hasan Oktay ${ }^{1}$, is with the Batman University, Batman, 72060 TURKEY. $\mathrm{He}$ is now with the Department of Mechanical engineering, (e-mail: hasan.oktay@batman.edu.tr).

Hakan Tutumlu ${ }^{2}$, was with Firat University, Elazığ, 72060 TURKEY. He is now with the Department of Mechanical engineering, (corresponding author's phone: +90-424-237 00 00; e-mail: htutumlu @ firat.edu.tr).

Recep Yumrutaş ${ }^{3}$ is with the Gaziantep University, Gaziantep, 27310 TURKEY. Department, He is now with the Department of Mechanical engineering, (e-mail: yumrutas@gantep.edu.tr). lag (TL), decrement factor (DF) and thermal mass that indicates the magnitude of heat loss and gains through building structures under periodic boundary conditions. Yumrutas et al. [2-4] developed an analytical methodology based on periodic solution of transient heat transfer problem for multi- layer walls and flat roofs to find heat gain through the structures and TETD values of the structures. The influence of wall orientation and exterior surface solar absorptivity on TETD values was also investigated. They obtained that higher solar radiation and ambient air temperatures give higher TETD values that lead to higher heat gains. Gasparella et al. [5] proposed a modification of the periodic thermal transmittance to evaluate the TL and DF of a wall which was subjected to the action of the sol-air temperature. Vijayalakshmi et al. [6] investigated the thermal behaviour of opaque wall materials under the influence of solar energy and analysed the influence of thermophysical properties of different wall types on the interior environment. Furthermore, several studies conducted about the effect of a wall's insulation layer distribution and thickness of dynamic thermal characteristics of the building components. They pointed out that the thickness and insulation position have a very profound effect on the heat gain or loss [7-10].

Studies cited above indicate that the dynamic thermal characteristics of the building components are influenced by the effective parameters, which can be categorized as environmental parameters (ambient air temperature, solar heat flux, ventilation etc.), design parameters (orientation, solar absorptivity, emissivity etc.) and thermophysical properties for a given building locating in a specific region. Many investigations declared that these characteristics strongly depend on the thermophysical properties of the building's layer materials [11-18]. For building heat transfer, the important thermophysical properties of a building component are thermal conductivity, specific heat, density, thickness and thermal diffusivity. The thermophysical properties of a building wall or roof material are strongly affected by microstructure, mineralogical composition, proportion, supplementary materials, moisture content, and porosity [19]. Besides, many investigations have indicated that there is a direct relationship among the specific heat, thermal 
conductivity, and thermal diffusivity of the building materials [20-23]. Although many researchers have attempted to investigate the effect of the each thermophysical properties of opaque components on their dynamic thermal characteristics, the current practices ignore the relationship between those properties. Since no research was conducted to inspect in detail the validity of these results for the realistic cases (in their analyses, the thermophysical properties of building elements have been considered as independent of each other), there is still a lack of information in the literature.

For this purpose, the effect of each thermophysical property on the hourly heat gain through the wall or roof regarding the relations among these properties has been investigated. In the previous study, 102 new concrete wall samples were produced, and their thermophysical properties were tested in accordance with ASTM and EN standards. Then, multivariate regression analyses were performed to evaluate possible correlations among the tested properties and expressions among these properties were obtained using the measurement data. In this study, an analytical periodic solution technique, Complex Finite Fourier Transform (CFFT) has been used for calculation of space heat gain through the walls or roofs the expressions obtained from the experimental study. Both experimental and theoretical procedures and their results are presented in detail in the following sections.

\section{II.FORMULATION OF HEAT TRANSFER MODEL}

\section{A. Periodic solution of transient heat transfer problem}

Heat transfer through a building wall or roof to room changes with ambient air temperature wall is a function of inner surface and sol-air temperatures. If the inner surface temperature of the wall can be obtained, heat transfer to the room can be calculated using this surface temperature, combined heat transfer coefficient at the surface, and the indoor temperature. Schematic view of a multilayer wall or roof consisting of a finite number of layers is shown in Fig. 1. The building structures consist of $\mathrm{N}$ layers and the nth layer of which has a thickness of $L_{n}$.

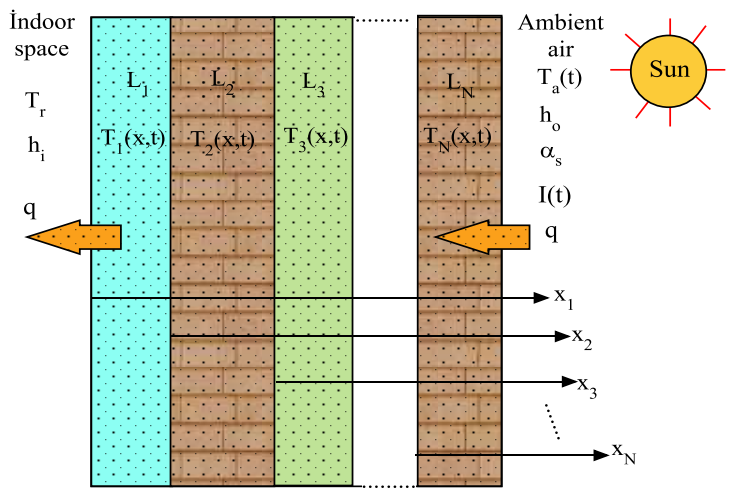

Fig. 1 Schematic view of a multilayer wall or roof consisting of a finite number of layers.

The heat transfer from the building structures is given as the following partial differential equations, boundary and matching conditions:

$$
\begin{array}{ll}
\frac{\partial^{2} \mathrm{~T}_{\mathrm{n}}}{\partial \mathrm{x}^{2}}=\frac{1}{\mathrm{a}_{\mathrm{n}}} \frac{\partial \mathrm{T}_{\mathrm{n}}}{\partial \mathrm{t}} & 1 \leq \mathrm{n} \leq \mathrm{N} \\
\mathrm{h}_{\mathrm{i}}\left(\mathrm{T}_{\mathrm{r}}-\mathrm{T}_{1}\right)=-\lambda_{1} \frac{\partial \mathrm{T}_{1}}{\partial \mathrm{x}_{1}} & \text { at } \mathrm{x}_{1}=0 \\
-\lambda_{\mathrm{n}-1} \frac{\partial \mathrm{T}_{\mathrm{n}-1}}{\partial \mathrm{x}_{\mathrm{n}-1}}\left(\mathrm{x}_{\mathrm{n}-1}=\mathrm{L}_{\mathrm{n}-1}\right)=-\lambda_{\mathrm{n}} \frac{\partial \mathrm{T}_{\mathrm{n}}}{\partial \mathrm{x}_{\mathrm{n}}}\left(\mathrm{x}_{\mathrm{n}}=0\right) \quad 2 \leq \mathrm{n} \leq \mathrm{N} \\
\mathrm{T}\left(\mathrm{x}_{\mathrm{n}-1}=\mathrm{L}_{\mathrm{n}-1}\right)=\mathrm{T}\left(\mathrm{x}_{\mathrm{n}}=0\right) & 2 \leq \mathrm{n} \leq \mathrm{N} \\
-\lambda_{\mathrm{N}} \frac{\partial \mathrm{T}_{\mathrm{N}}}{\partial \mathrm{x}_{\mathrm{N}}}=\mathrm{h}_{\mathrm{o}}\left[\mathrm{T}_{\mathrm{N}}-\mathrm{T}_{\mathrm{e}}(\mathrm{t})\right] & \text { at } \mathrm{x}_{\mathrm{N}}=\mathrm{L}_{\mathrm{N}} \\
\mathrm{T}_{\mathrm{e}}(\mathrm{t})=\mathrm{T}_{\mathrm{a}}(\mathrm{t})+\frac{\alpha_{\mathrm{s}} \mathrm{I}_{\mathrm{T}}(\mathrm{t})}{\mathrm{h}_{\mathrm{o}}}-\frac{\varepsilon \Delta \mathrm{R}}{\mathrm{h}_{\mathrm{o}}} & \text { at } \mathrm{x}_{\mathrm{N}}=\mathrm{L}_{\mathrm{N}}
\end{array}
$$

where $n$ refers to the layer number, i.e. $n=1,2, \ldots, N, h_{i}$ and $h_{o}$ are the combined convection heat transfer coefficients at the inner and outer surfaces, respectively. $T_{e}(t)$ is the hourly sol-air temperature, $T_{l}=T_{x=0}$ and $T_{N}=T_{x=N}$ the temperatures of the inner and outer surfaces of the wall, respectively. The last term in Eq. (6), is defined as the correction factor ASHRAE [24], which is specified to be $4^{\circ} \mathrm{C}$ for horizontal surfaces facing up. For vertical surfaces, the correction factor is specified to be $0^{\circ} \mathrm{C}$ as the warmer sunlit surfaces compensate for the cooler sky temperature. $I_{T}(t)$ is the hourly solar heat flux on a tilted surface, which is equal to the intensity of solar radiation falling on unit area flux. It can also be expressed as the sum total of the beam, diffuse and reflected radiation which is given and discussed in Duffie and Backman [25]. The transient heat transfer problem consisting of Eqs. (1)-(6) will be put into dimensionless form and solved to obtain a periodic solution by an application of the CFFT. The procedures for each component of the theoretical model, which were developed by Yumrutas et al. [2], are discussed in detail and presented as:

$$
\begin{array}{ll}
T_{n}(0, \tau)=\sum_{j=-M}^{M} T_{n j}(0) e^{i \omega_{j} \tau} & \text { at } z_{n}=0 \\
q=h_{i}\left[T_{n}(0, \tau)-T_{r}\right] & \text { at } z_{n}=0
\end{array}
$$

where $q$ is the heat flux $\left(\mathrm{W} / \mathrm{m}^{2}\right)$ through indoor space of a building from exterior walls. $z_{n}, \tau, \omega_{j}$, and $T_{n j}$ are dimensionless parameters, $T_{r}$ is the indoor air temperature $M$ is the large number and generally taken as 60 .

\section{B. Comparison of heat gain values}

In this section, in order to show the reliability of the present study, we will compare the calculated heat gain values by the CFFT method with the heat gains in a literature model. In the model, an illustration of the problem is presented in Jin et al. [14] that analyses two parameters, which are the heat flux time lag and decrement factor, are proposed to evaluate the thermal performance of the wall. Based on the one-dimensional numerical model built in this model, the effects of the thermophysical properties of the wall on the "total heat flux" 
per day are investigated.

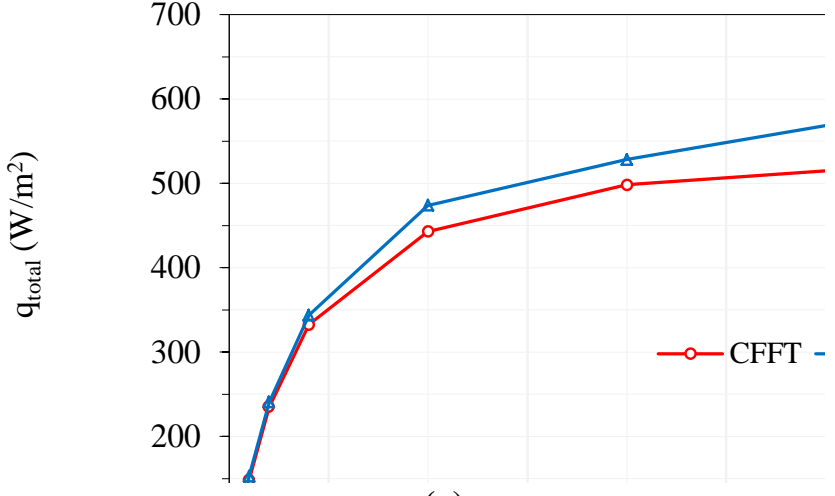

(a)

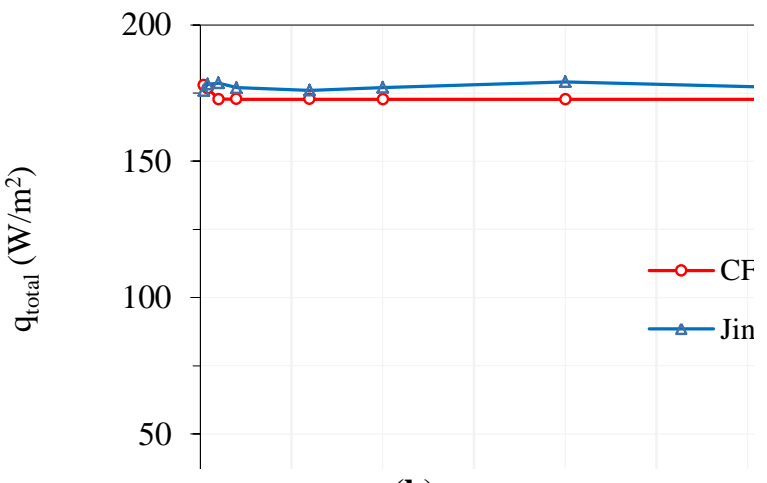

(b)

Fig. 2 A comparison between the method of Jin et al. and CFTT in the calculation of total heat flux per day due to the variation of thermophysical properties for a building wall: (a) with constant heat capacity (b) constant thermal conductivity.

The comparison of heat gain values for the selected wall in Jin et al. [14] with those obtained from the CFTT is showed in Fig. 2. In both models, the solar-air temperature is assumed to be sinusoidal variations during a $24-\mathrm{h}$ period. The interior design air temperature, $T_{r}$, the combined heat transfer coefficients at the interior, $h_{i}$ and exterior surfaces, $h_{o}$ are considered as $26{ }^{\circ} \mathrm{C}, 8.7$ and $18.6 \mathrm{~W} / \mathrm{m}^{2}{ }^{\circ} \mathrm{C}$, respectively. In Fig. 2 (a), the thermal conductivity of the wall is varied between $0.05 \mathrm{~W} /(\mathrm{m} \mathrm{K})$ and $20 \mathrm{~W} /(\mathrm{m} \mathrm{K})$ and the thermal capacity of the wall is held constant as $1.512 \mathrm{MJ} /\left(\mathrm{m}^{3} \mathrm{~K}\right)$. In Fig. 2 (b), the thermal capacity of the wall is varied between $0.1 \mathrm{MJ} /\left(\mathrm{m}^{3} \mathrm{~K}\right)$ and $20 \mathrm{MJ} /\left(\mathrm{m}^{3} \mathrm{~K}\right)$ and the thermal conductivity of the wall is held constant as $0.62 \mathrm{~W} /(\mathrm{m} \mathrm{K})$. When the results are compared to each other, it can be observed that the heat gain values calculated by the CFFT method are in good agreement with the results of Jin et al. except for the calculated total heat flux values using the high thermal conductivity value of $20 \mathrm{~W} /(\mathrm{m} \mathrm{K})$. However, in Jin et al., the estimation of heat flux values based on the assumptions is unreasonable because the relationships between the thermophysical properties of the wall material are taken into account as independent of each other. This conflict is discussed thoroughly in the following sections.

\section{EXPERIMENTAL STUDY}

\section{A. Materials and test procedures}

In a previous study [20], the experimental research aimed to produce different wall types to establish the relationships between the thermophysical properties by performing a set of consistent tests. In this regard, the mixtures were produced as normal concrete (NC), air-entrained concrete (AEC), pumice concrete (PC), expanded perlite concrete (EPC), and rubberized concrete (RC) and the numbers 10, 20, 30, 40 and 50 show the percentage of replacement. The chemical composition and physical properties of the materials, as well as preparation of concrete mixtures for this study, were explained in detail [20]. Thermophysical and mechanical tests were carried out to establish the physical properties of the wall samples, including density, thermal conductivity, specific heat and thermal diffusivity, incorporating PC, EPC and RC. The mechanical tests were performed on air-dry specimens 28 days after they were prepared. The thermophysical tests were performed on air-dried samples 35 days after sample preparation, as according to EN 12667 [26]. All test result measurement values presented in the tables are based on the average values \pm a tolerance limit (less than $4 \%$ ) in order to cover the range of all properties as measured for different samples of the same category.

\section{B. Correlations between the thermophysical properties}

The experimental results for the density, thermal conductivity, specific heat and heat capacity tests are presented in Table 1.

TABLE I

THERMOPHYSICAL PROPERTIES OF PRODUCED CONCRETE WALLS*

\begin{tabular}{lcccc}
\hline $\begin{array}{l}\text { Types of } \\
\text { concrete }\end{array}$ & $\begin{array}{c}\text { Bulk } \\
\text { density, } \\
\rho\left(\mathrm{kg} / \mathrm{m}^{3}\right)\end{array}$ & $\begin{array}{c}\text { Thermal } \\
\text { conductivity, } \\
\lambda(\mathrm{W} /(\mathrm{m} \mathrm{K}))\end{array}$ & $\begin{array}{c}\text { Specific heat, } \\
c(\mathrm{~J} / \mathrm{kg} \mathrm{K})\end{array}$ & $\begin{array}{c}\text { Heat capacity, } \\
\rho c\left(\mathrm{MJ} /\left(\mathrm{m}^{3} \mathrm{~K}\right)\right)\end{array}$ \\
\hline NC & 2345.09 & 1.96 & 709.07 & 1,66 \\
AEC & 2288.86 & 1.91 & 712.14 & 1,63 \\
EPC10 & 2139.09 & 1.51 & 725.48 & 1,55 \\
EPC20 & 1885.52 & 1.22 & 779.63 & 1,47 \\
EPC30 & 1559.44 & 0.70 & 865.69 & 1,35 \\
EPC40 & 1376.56 & 0.50 & 922.59 & 1,27 \\
EPC50 & 1168.63 & 0.36 & 966.95 & 1,13 \\
PC10 & 2005.34 & 1.54 & 772.42 & 1,55 \\
PC20 & 1851.02 & 1.29 & 818.52 & 1,52 \\
PC30 & 1559.95 & 0.76 & 903.87 & 1,41 \\
PC40 & 1400.72 & 0.54 & 949.51 & 1,33 \\
PC50 & 1329.97 & 0.41 & 991.80 & 1,32 \\
RC10 & 2244.30 & 1.72 & 721.83 & 1,62 \\
RC20 & 2148.07 & 1.44 & 737.70 & 1,58 \\
RC30 & 2033.93 & 1.22 & 761.20 & 1,55 \\
RC40 & 1874.62 & 0.89 & 808.93 & 1,52 \\
RC50 & 1644.98 & 0.62 & 868.16 & 1,43 \\
\hline These properties are the average of the six specimens & \\
\hline
\end{tabular}

* These properties are the average of the six specimens for each test.

The accuracy of the regression model is calculated by the 
square of multiple determination coefficient, $R^{2}$. The closer $R^{2}$ to unity, the better the model fits the data. The curves for series of the mixtures are plotted, and the best-fit curve is generally represented by an exponential curve for each tested samples. The following expressions regarding thermophysical properties are expressed as a function of the dry density with $\mathrm{R}^{2}=0.95[20]$ :

$$
\lambda=0.0676 \mathrm{e}^{0.0015 \rho}
$$

The variation obtained is similar to that reported in previous works conducted among lightweight concretes and other building materials [27-29]. Furthermore, the other expressions obtained from the same analysis are presented as a function of the dry density $[20]\left(R^{2}=0.97\right)$ :

$$
\mathrm{c}=1427.1 \mathrm{e}^{-0.0003 \rho}
$$

The results clearly indicate a strong correlation between the density and the other properties of the wall samples. All relations obtained among the tested properties are explained and discussed in detail [20].

\section{COMPUTATION PROCEDURE}

Accurate estimation of transient heat transfer problem for a building wall is quite complicated and time-consuming since it is highly transient in nature due to both thermal storage effects of the building mass and ever changing external conditions. Therefore, a computer program in MATLAB was prepared by using climatic data and thermophysical properties of the produced samples. The program uses the following parameters as input: hourly solar radiation flux on the horizontal surface, thermophysical properties of the building materials, combined convection heat transfer coefficient for both sides of inside and ambient air, hourly ambient air temperature and inside design air temperature. The climatic data, which are hourly ambient air temperature and solar radiation on a horizontal surface, were measured by meteorological stations for Gaziantep province (latitude: $37.04{ }^{\circ} \mathrm{N}$, longitude: $37.31^{\circ} \mathrm{E}$ ) on July 21 . In order to obtain more reliable results, hourly solar radiation and ambient temperatures measured in Gaziantep for ten years between 2003 and 2013 were taken. The interior design air temperature, the combined heat transfer coefficients at the interior and exterior surfaces are taken to be $24{ }^{\circ} \mathrm{C}, 8.3$ and 17 $\mathrm{W} / \mathrm{m} 2{ }^{\circ} \mathrm{C}$, respectively. Solar absorptivity ( $\alpha$ s in Eq. (9)) which depends on the external face colour of a building envelope, is generally assumed to be 0.884 (dark coloured surface).

\section{V.RESULTS AND DISCUSSIONS}

The solar radiation incident $\left(\mathrm{W} / \mathrm{m}^{2}\right)$ on horizontal and vertical surfaces, mean values of hourly ambient air temperatures and variations of sol-air temperature for south direction are indicated in Fig. 3 for the city of Gaziantep.

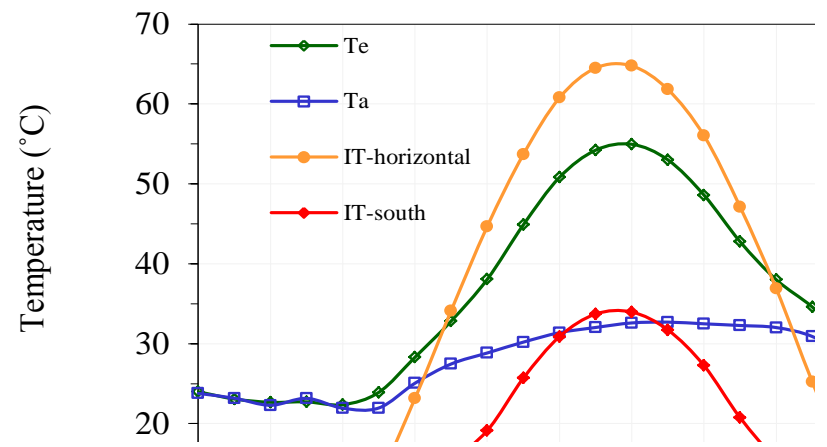

Fig. 3 The solar radiation incident on horizontal and vertical surfaces, mean values of hourly ambient air temperatures and variations of solair temperature due to south direction.

In order to make an accurate comparison between the heat gain values obtained from both the assumptions and the experimental result, the value of the materials' thermophysical property is selected in tested range, which is large enough to cover most common elements in building construction that can be used for both structural (beam, column) and non-structural (wall, roof) purposes. Furthermore, the theoretical calculations are carried out for $24 \mathrm{~cm}$ three-layered wall $(2 \mathrm{~cm}$ plaster +20 $\mathrm{cm}$ wall material $+2 \mathrm{~cm}$ plaster) directed to the south.

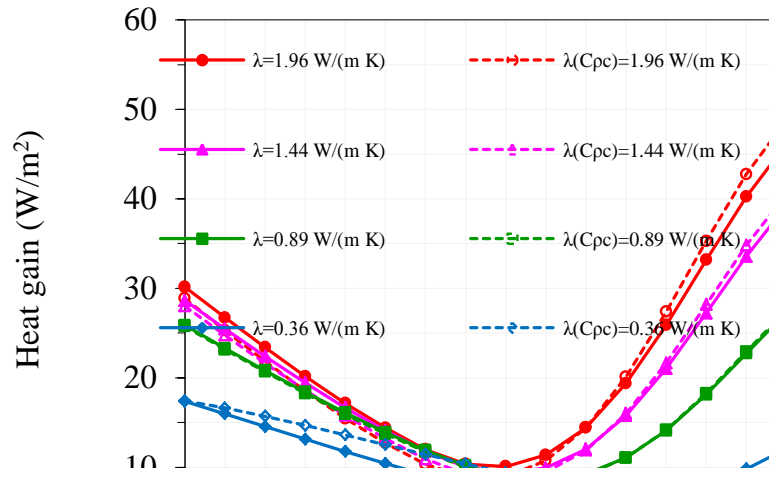

Fig. 4 Comparison of the effect of the thermal conductivity on the heat gain values through a wall for the assumption and experimental model.

Fig. 4 presents the effect of the thermal conductivity on the heat gain values for south facing wall and roof constructions. In the calculations, the thermal conductivity of the structures is varied from $0.36 \mathrm{~W} /(\mathrm{m} \mathrm{K})$ to $1.96 \mathrm{~W} /(\mathrm{m} \mathrm{K})$, and the thermal capacity is taken as a constant average value of $1.50 \mathrm{MJ} /\left(\mathrm{m}^{3}\right.$ $\mathrm{K})$. It can be observed that the calculated heat gain values have similar tendencies: increasing of thermal conductivity increases the heat gain values. This is owing to the fact that when the density and specific heat values are fixed (constant heat capacity) in the assumption model, an increase in the thermal conductivity leads to increase the values of thermal diffusivity. In the experimental study, an inverse relationship exists between specific heat and density; thereby, a direct relationship exists between the density and thermal 
conductivity as presented in Exps. (12) and (13), respectively. Because an increase in the density value is greater than a decrease in the specific heat of materials, increase of both thermal conductivity and density also leads to increase in the thermal diffusivity values. Moreover, similar heat gain values are obtained for the thermal conductivity of $0.89 \mathrm{~W} /(\mathrm{m} \mathrm{K})$ in both models because the used heat capacity values are close to each other, which are $1.50 \mathrm{MJ} /\left(\mathrm{m}^{3} \mathrm{~K}\right)$ and $1.52 \mathrm{MJ} /\left(\mathrm{m}^{3} \mathrm{~K}\right)$, respectively. When a different constant value is utilised in assumption model, the calculated heat gain values are different from each other as depicted Fig. 4. The results reveal that thermal conductivity is a strong property such that any type of structure with higher thermal conductivity has higher heat gain values in a building. High level of heat gain values indicates high difference in outer and inner temperatures that causes uncomfortable conditions.

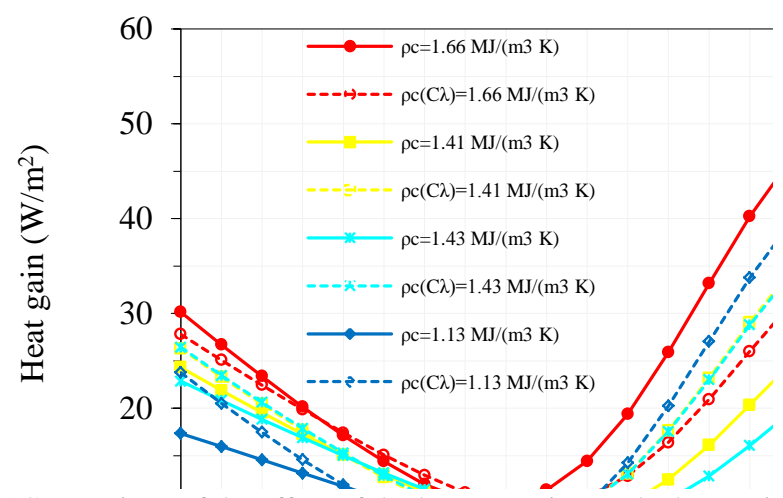

Fig. 5 Comparison of the effect of the heat capacity on the heat gain values through a wall for the assumption and experimental model.

In concrete or concrete masonry, the heat capacity of a wall is determined by multiplying the wall mass per area $(\mathrm{kg} / \mathrm{m} 2)$ by the specific heat $(\mathrm{J} / \mathrm{kg}$. K) of the wall material. More simply, it is the product of a density and its specific heat. Fig. 5 depicts the effects of the heat capacity variations on the heat gain values for south facing wall and roof constructions. In the calculations, the heat capacity of the structures is varied from $1.13 \mathrm{MJ} /\left(\mathrm{m}^{3} \mathrm{~K}\right)$.to $1.66 \mathrm{MJ} /\left(\mathrm{m}^{3} \mathrm{~K}\right)$ in tested range, and the thermal conductivity is taken as a constant average value of $1.09 \mathrm{~W} /(\mathrm{m} \mathrm{K})$. Fig. 5 indicates a very remarkable result that there is a nearly linear relationship between the amplitude of heat gain values and the heat capacity: increasing of heat capacity generally, increases the heat gain values. However, this is not a general case that the heat gain values through the PC30 wall or roof $\left(\rho c=1.41 \mathrm{MJ} /\left(\mathrm{m}^{3} \mathrm{~K}\right)\right)$ is greater than the heat gain values for the RC50 wall $\left(\rho c=1.43 \mathrm{MJ} /\left(\mathrm{m}^{3} \mathrm{~K}\right)\right)$ despite its low heat capacity. Therefore, the degree of relationship between the heat gains versus heat capacity is much weaker than the other properties such as thermal conductivity. On the contrary, in assumption model, an increase of the heat capacity leads to a decrease in the thermal diffusivity at constant thermal conductivity. Moreover, References [12-16] claim that as the heat capacity goes to its maximum value, the heat gain value (also decrement factor) goes to its minimum value; thereby, the stored heat energy in the building envelope can sustain an almost constant inner wall temperature. These results can be theoretically correct; however, it is not a realistic situation. In general, heat capacity is not an effective property to indicate the thermal performance of building materials, since metals have very high thermal capacities, and the thermal conductivities of them are also very high. Thereby, some insulation materials (formaldehyde board, polyurethane board) have very low thermal conductivities and the thermal capacities of them are also very low owing to their much lower density

\section{CONCLUSION}

In this study, both experimental and theoretical investigations were carried out to establish the effect of each thermophysical properties on heat gain through building wall. The following main conclusions can be drawn from this study:

1. The results show that the assumptions proposed in the literature are not realistic in a significant number of cases: the authors ignored the relationships among the thermophysical properties in the calculations of dynamic thermal characteristics of building components. Thermophysical properties of a wall or roof are very effective in terms of heat transfer of a building wherein each property alone (without considering other properties) is not adequate to characterise the thermal inertia and thermal performance of a building structure.

2. This result reveals that thermal conductivity and density have a very profound effect on the heat gain where any type of structure with higher thermal conductivity and density has higher heat gain values in a building. On the contrary, the degree of the relationship between heat gain and heat capacity is weaker than the other properties.

\section{REFERENCES}

[1] K. Bansal, S. Chowdhury, M. R. Gopal, "Development of CLTD values for buildings located in Kolkata, India," Applied Thermal Engineering, vol. 28, 2008, pp. 1127-1137.

[2] R. Yumrutas, M. Unsal, M. Kanoglu, "Periodic solution of transient heat flow through multilayer walls and flat roofs by complex finite Fourier transform technique," Building and Environment, vol. 40, 2005, pp. 1117-25.

[3] R. Yumrutas, O. Kaska, E. Yıldırım, "Estimation of total equivalent temperature difference values for multilayer walls and flat roofs by using periodic solution," Building and Environment, vol. 42, 2007, pp. 18781885.

[4] O. Kaska, R. Yumrutas, O. Arpa, "Theoretical and experimental investigation of total equivalent temperature difference (TETD) values for building walls and flat roofs in Turkey," Applied Energy, vol. 86, 2009, pp. 737-747.

[5] A. Gasparellaa, G. Pernigottob, M. Baratieri, P. Baggioc, "Thermal dynamic transfer properties of the opaque envelope, Analytical and numerical tools for the assessment of the response to summer outdoor conditions,” Energy and Building, vol. 43, 2011, pp. 2509-2517.

[6] M. M. Vijayalakshmi, E. Natarajan, V. Shanmugasundaram, "Thermal behaviour of building wall elements," Journal of Applied Science, vol. 15, 2006, pp. 3128-3133.

[7] S. A. Al-Sanea, M. F. Zedan, "Improving thermal performance of building walls by optimizing insulation layer distribution and thickness for same thermal mass," Applied Energy, vol. 88, 2011, pp. 3113-3124. 
[8] H Asan, "Investigation of wall's optimum insulation position from maximum time lag and minimum decrement factor point of view," Energy and Building, vol. 32, 2000, pp. 197-203.

[9] H. Asan, "Effects of Wall' s insulation thickness and position on time lag and decrement factor," Energy and Building, vol. 28, 1998, pp. 299305.

[10] M. Ozel, "Effect of insulation location on dynamic heat-transfer characteristics of building external walls and optimization of insulation thickness," Energy and Building, vol. 72, 2014, pp. 288-295.

[11] Y. Zhang, Q. Chen, Y. Zhang, X. Wang, "Exploring buildings' secrets, The ideal thermophysical properties of a building's wall for energy conservation," International Journal of Heat and Mass Transfer, vol. 65, 2013, pp. 265-273.

[12] H. Asan, "Numerical computation of time lags and decrement factors for different building materials," Building and Environment, vol. 41, 2006, pp. 615-620.

[13] Asan H, Sancaktar YS, "Effects of Wall's thermophysical properties on time lag and decrement factor," Energy and Building, vol. 28, 1998, pp. $159-166$.

[14] X. Jin, X. Zhang, Y. Cao, G. Wang, "Thermal performance evaluation of the wall using heat flux time lag and decrement factor," Energy and Building, vol. 47, 2012, pp. 369-374.

[15] Y. Zhang, K. Lin, Q. Zhang, H. Di, "Ideal thermophysical properties for free-cooling (or heating) buildings with constant thermal physical property material," Energy and Building, vol. 38, 2006, 1164-70.

[16] Y. Zhang, K. Dua, J. Hec, L. Yanga, Y. Lia, S. Lia, "Impact factors analysis on the thermal performance of hollow block wall," Energy and Building, vol. 75, 2014, pp. 330-341.

[17] K. J. Kontoleon, Th. G. Theodosiou, K. G. Tsikaloudaki, "The influence of concrete density and conductivity on walls' thermal inertia parameters under a variety of masonry and insulation placements," Applied Energy, vol. 112, 2013, pp. 325-337.

[18] G. Barrios, G. Huelsz, R. Rechtman, J. Rojas, "Wall/roof thermal performance differences between air-conditioned and non airconditioned rooms," Energy and Building, vol. 43, 2011, pp. 219-223.

[19] M. I. Khan, "Factors affecting the thermal properties of concrete and applicability of its prediction models," Building and Environment, vol. 37, 2002, pp. 607-614.

[20] H. Oktay, R. Yumrutas, A. Akpolat, "Mechanical and thermophysical properties of lightweight aggregate concretes," Construction and Building Materials, vol. 96, 2015, pp. 217-225.

[21] O. Unal, T. Uygunoglu, A. Yildiz, "Investigation of properties of lowstrength lightweight concrete for thermal insulation," Building and Environment, vol. 42, 2007, pp. 584-590.

[22] H. Canakci, R. Demirboga, B. Karakoc, O. Sirin, "Thermal conductivity of limestone from Gaziantep (Turkey)," Building and Environment, vol. 42, 2007, pp. 1777-1782.

[23] ACI Committee 122, Guide to Thermal Properties of Concrete and Masonry Systems, ISBN 9780870310850, 2002

[24] ASHRAE. ASHRAE handbook-fundamentals, Atlanta: ASHRAE, 1993.

[25] J. A. Duffie, W. A. Beckman, Solar engineering of thermal process, 4th ed. New York: Wiley, 2013.

[26] TS EN 12667 Turkish Standards Institute. Thermal performance of building materials and products, 2003. 